\title{
DESCRIPTION OF SLEEP QUALITY, PHYSICAL ACTIVITY, AND DEHYDRATION STATUS AMONG BATIK WORKERS IN BANTUL, YOGYAKARTA
}

\author{
Perdana Samekto, Khalisa Khairani, Yayuk Hartriyanti \\ Department of Health Nutrition, Faculty of Medicine/Public Health/Nursing, \\ Universitas Gajah Mada
}

\begin{abstract}
Background: Previous studies have shown that physical exercise is associated with an improved mood and increased job performance. A lack of sleep is associated with lower satisfaction with life, health, work, and financial well-being. Poor sleepers are significantly less resilient and optimistic and more stressed than good sleepers. This study aimed to describe sleep quality, physical activity, and dehydration status among batik workers in Bantul, Yogyakarta.

Subjects and Method: This was a descriptive cross-sectional study conducted in Bantul, Yogyakarta. A total of 78 batik workers were selected for this study. Variables for this study were sleep quality, physical activity, and dehydration status. Data on hydration status was obtained by urine in the morning. The other data were collected by questionnaire. The data were described in percent.

Results: As many as $43.6 \%$ of the batik workers had moderate activity, $79.5 \%$ had poor sleep quality, and $47.4 \%$ were in mild dehydration. The poor quality of sleep was indicated by sleep duration $<5$ hours and sleep efficiency $<65 \%$.

Conclusion: The majority of the batik workers have moderate activity level, poor quality of sleep, and mild dehydration.
\end{abstract}

Keywords : sleep quality, physical activity, dehydration, batik worker.

\section{Correspondence:}

Perdana Samekto. Department of Health Nutrition, Faculty of Medicine/Public Health/Nursing, Universitas Gajah Mada, Yogyakarta, Indonesia.

Email: perdana.sts@gmail.com. Mobile: 085110433785 